\title{
Socioeconomic correlates and the choice of treatment for childhood fever in Ghana
}

\author{
Eric Arthur \\ Department of Economics and Statistics \\ University of Benin, Benin City, Nigeria. \\ earthur3@gmail.com
}

\begin{abstract}
The study investigated the effect of household socioeconomic factors on the choice of treatment for childhood fever among children under age five in Ghana. Data from the 2008 Ghana Demographic and Health survey was used employing the multinomial probit model. Three treatment choices were considered: Government facility, Private facility and traditional/self-medication. The results suggest that the treatment of childhood fever is related to household wealth, health insurance status and residence. Government health facilities are mostly used by household's with higher wealth and household's with health insurance. Rural households are more likely to use traditional/self-medication, except those with health insurance who use government facilities. The age of the mother and birth order of the child were also found to influence the choice of treatment facility for childhood fever.
\end{abstract}

Keywords: Fever, socioeconomic, childhood, treatment, health

\section{Résumé}

Cette étude analyse l'effet des facteurs socio-économiques des ménages sur le choix du traitement de la fièvre chez les enfants de moins de cinq ans au Ghana. Les données de l'enquête démographique et de santé du Ghana sont analysées à l'aide d'un modèle probit multinomial. Trois moyens de traitements ont été considérés: public, privé, traditionnel/auto médication. Les résultats suggèrent que le traitement de la fièvre chez l'enfant est lié au niveau de revenu des ménages, au fait qu'ils aient une assurance santé ou pas et à leur milieu de résidence. Les établissements de santé publics sont principalement utilisés par les ménages ayant un niveau de revenu élevé et par les ménages ayant une assurance santé. Les ménages ruraux sont plus susceptibles d'utiliser des médicaments traditionnels ou de recourir à l'automédication, sauf ceux avec une assurance santé qui utilisent les établissements de santé publics. L'âge de la mère et l'ordre de naissance de l'enfant affectent également le choix du moyen de traitement.

Mots-clés: Fièvre, socio-économique, enfance, traitement, santé

\section{Introduction and Background}

The World Health Organization (WHO) defined health in its broader sense in 1946 as "a state of complete physical, mental, and social well-being and not merely the absence of disease or infirmity". A healthy person is not just that person who is not sick, but he/she is able to participate fully in all aspects of the economy due to good health. Indeed, Nobel Laureate Amartya Sen postulates that health, like education, is among the basic capabilities that gives value to human life; hence, poor health is also a capability deprivation to the individual. The health of an individual is one of the necessities to live and serves as the platform upon which the individual develops other capabilities such as education; good health permits the person to survive in the academic environment. This is particularly important for the child since the health status of the child has important influence on adult health as many diseases that emerge in adult life have their origins much earlier in the life course of the person as a child. Such diseases are also known to contribute to the high rate of under-five mortality in Sub Saharan Africa.

The WHO (20I I) reports that the world average for under-five mortality rate (U5MR) has fallen from $87 / 1000$ to $5 \mathrm{I} / 1000$ live births. However, the result for Africa is still high at $150 / 1,000$ on average compared to Europe and the USA with an average of 20/1,000. Existing research evidence has shown that one factor that contributes to the poor health outcomes of children is the socioeconomic status of 
the family since the child depends on the family for survival and for protection at that early stage. Poor child health can lead to increased child morbidly and mortality.

Socioeconomic status refers to the level of social and economic position of an individual within the society as reflected by various indicators such as income /wealth, education, employment, type of occupation, etc. Existing literature shows a complex interplay of social and economic factors that ultimately determines people's standard of living and their command over goods and health services. For instance, wealth/income affects child health adversely through malnutrition, poor hygienic conditions, lack of awareness and proper health care in the event of illness. Poor nutrition of the child may also contribute to poor school performance, as a malnourished child may perform poorly in school. Education of the parent is also an important contributor to the development of the child. The effect of education can be either positive or negative; educated parents are more likely to be engaged in more demanding jobs, which leaves them with little time to cater for their children, hence, may affect the chances of the child getting good care in the event of illness. It can however be argued contrary that educated parents are better users of health capital following the arguments of the Grossman's (1972) health capital model and hence perform better in giving their children better health care than their counterparts who are not educated. Similarly, other social factors such as residence, marital status and even accessibility of health care services may have a significant effect on one's health and that of the child who depends on him/her.

Several health and development policies have focused on improving the wellbeing of the mother and child. According to Elo (1992), one of the objectives of primary health care programs in developing countries was to improve child survival through improved utilization of preventive maternal and childcare services. The Millennium Development Goals (MDG's) seek to improve the health of the child and mother by improving the health services provided to both mother and child. Despite these efforts, Africa continues to battle with poor child health outcomes. World Bank (2006), reports, "Sub-Saharan Africa is not on track to achieve a single MDG. In addition to other goals, it is off track on the hunger goal-and it is the only region where child malnutrition is not declining...." The United Nations Children's Fund and the World Health Organization (2004) reports that 85 percent of malaria deaths, and 95 percent of all new episodes of pneumonia worldwide occur annually in children under-five years of age in Africa. These diseases are mostly precluded by the incidence of fever. It is thus important to address these concerns in a bid to achieve improved health.

Fever is a common symptom of illness mostly associated with malaria, pneumonia and other child health conditions. Fever is a rise in temperature to levels that are considered to be above normal and gives a signal of the existence of an underlying health condition that needs to be treated, especially in young children. Mostly in children under age five, the mother or caregiver who has constant contact with the child easily notices it. Malaria and pneumonia are a major cause of under-five morbidity and mortality worldwide. The WHO report on Infectious Diseases posits that infectious diseases and malaria in particular, are a consequence of poverty as well as an obstacle that keeps people in poverty and that these diseases cause most of the deaths from infectious diseases. According to WHO (2006) World Malaria Report, malaria is prevalent in more than 100 countries worldwide and about 1.2 billion people representing $20 \%$ of the world's population are at high risk of malaria, with $49 \%$ of this population living in Africa. In 2006, $91 \%$ of the world's $88 \mathrm{I}, 000$ malaria deaths occurred in SubSaharan Africa. Previous studies have indicated that key strategies for control of such diseases are based on early diagnosis and appropriate treatment. The success of this strategy depends, however, on understanding the socioeconomic factors influencing health care decision making at the household level.

In Ghana, malaria and pneumonia are leading causes of childhood morbidity and mortality. Malaria accounts for the majority of childhood hospital admissions and 26 percent of childhood deaths, while pneumonia is responsible for about 22 percent of hospital admissions in tertiary health facilities and 18 percent of childhood deaths (Nonvignon et al, 2010). Thus, as a first step to addressing this problem, parents and caregivers need to seek appropriate and prompt care for the child upon noticing the presence of fever in the child. Thus, more childhood deaths would be averted if caregivers would appropriately seek care, receive it and apply treatment correctly. Acquiring information on the factors influencing health-seeking behavior of parents is particularly important as part of actions needed if Ghana and other developing countries are to achieve the Millennium Development Goal 4 aimed at reducing child 
mortality by 2015 and to improve the health outcomes of children. This study therefore seeks to assess the socioeconomic factors that influence the decision of mothers/caregivers to seek treatment for children under five in Ghana to inform policy in reducing childhood morbidity and mortality in Ghana.

\section{Literature Review}

Previous studies on the factors driving the choice of facility for treatment of childhood diseases have reported the importance of factors such as income/wealth, residence, access to health care centres, and other social factors like education and age that are important in the decision to seek care for the sick child. For instance, Goldmana, Pebleyb, and Gragnolatic, (2002), use the 1995 Guatemalan Survey of Family Health to analyze the relationship between child illness and health seeking behavior. The results from the study indicated that modern medical care plays a major role in the treatment of infectious illness among children in rural Guatemala. The symptoms associated with the illness, their perceived severity, and mother's beliefs about their causes were identified in the study as important determinants of whether a child is brought to a provider and the type of provider visited. Poverty was identified as a serious constraint on a family's choices about how to treat children's illnesses, whereas education and ethnicity were reported to have little effect on treatment behavior when income is held constant. In addition, the availability of modern health facilities within the community, both government-sponsored facilities and private doctors had a substantial impact on the type of providers sought to treat children's illnesses, according to the study, hence confirming the importance of income and accessibility/ availability of health services on seeking care for the sick child..

Likewise, Arif (2007) employing the ordinary least squares technique examined the health status of Pakistani children using morbidity and malnutrition. The study reported that distance to the nearest health facility had significantly negative influence on child morbidity, implying that the longer the distance, the lesser the probability of getting treatment for a sick child hence influencing child morbidity, except for families with adequate resources. Filmer (2005) also used data from the demographic and Health surveys of 22 sub-Saharan African (SSA) countries to explore the associations between household wealth and the incidence and treatment of fever, as an indicator of malaria, among children in sub-Saharan Africa, using both the bivariate and multivariate probit model. The findings suggest that the incidence of fever and its treatment are related to poverty (as measured by wealth) in sub-Saharan Africa. The study indicated that the incidence of fever is lower for the wealthiest households, and treatment patterns are strongly related to poverty, as wealthier households are more likely to seek care for the child. In addition, Malik et al, (2006) reports that the main healthseeking behaviour for malaria in children under age five is to consult the nearest health facility or health personnel together with using traditional medicine or herbs. The majority of mothers with febrile children according to the study reported taking drugs before visiting a health facility. The choice between the available options was determined by the availability of health facilities, user fees, and satisfaction with services, difficulty to reach the facilities and believe in traditional medicine.

Kazembe et. al., (2007) concluded that factors that affects the choice of treatment for malaria in Malawi included place of residence, access to media, care-givers age and care factors including unavailability and inaccessibility of care. Additionally, Chibwana et al, (2009) reported in Malawi that despite the high knowledge of malaria among mothers, prompt treatment, and health-seeking behaviour was poor, with the majority of children first being managed at home with treatment regimens other than effective anti-malarial drugs. The reasons accounting for this, according to the paper was due to traditional beliefs about causes of fever, unavailability of anti-malarial drugs within the community, barriers to accessing the formal health care system, and trust in traditional medicine.

Nonvignon et al, (2010) used data from a 2006 household socio-economic survey and health and demographic surveillance covering caregivers of 529 children under-five years of age in the Dangme West District in Ghana and applied a multinomial probit technique to model the choice of treatment services for fevers in under-fives in rural Ghana. The findings indicated that longer travel, waiting, and treatment times encourage people to use self-medication and over-the-counter providers whereas caregivers with health insurance coverage also use care from public providers. Caregivers with higher incomes use public and private providers over self-medication while higher treatment charges and longer times at public facilities encourage caregivers to resort to private providers. Besides, caregivers of female 
under-fives use self-care while caregivers of male under-fives use public providers.

In contrast to the studies above, Rutebemberwa et al (2009) reported no significant differences between age, sex and education of the household head, age and sex of the children and socioeconomic status of the households among those who had used drug shops/private clinics and those who went to government facilities seeking treatment for the sick child in Uganda. The study however reported that caregivers sought treatment for the sick child from government health facility upon realizing that the sick child is vomiting and perceiving that the health providers were qualified or experienced in the health facility. On the other hand, those who took the febrile child to drug shops/private clinics did so because they were going there to get first aid.

\section{Data and Methods}

The study uses secondary data on children under age five from the 2008 Ghana Demographic and Health Surveys (GSS 2009). The Ghana Demographic and Health Survey (GDHS) is a nationwide survey funded by the United States Agency for International Development (USAID), and implemented by ORC Macro Incorporated. It is carried out once every five years. The strategic objective of the Measure DHS is to improve and institutionalize the collection and use of data on reproductive health by host countries for program monitoring and evaluation and for policy development decisions. It contains data on children and women health in addition to the demographic profile of the households/individuals.

The dependent variable is the choice of facility for the treatment of childhood fevers. The choice of facility for treatment for fever is a multinomial variable with three categories Self-medication/ traditional medicine, Government facility (including hospital, health centre, health post, and clinics), and Private hospital/clinic). This is modeled on the family socioeconomic characteristics, particularly that of the mother due to the heavy reliance of the child at that age on the mother. These include wealth, education, residence, employment, marital status and access to health care (measured by distance and transportation to the nearest health facility). The specific characteristics of the child (gender, and birth order) are also being controlled for in the study.

The demand for health for the sick child in this analysis is modeled following the Grossman (1972) model on health capital and demand for health care. Since the child under age five depends primarily on the parents for decisions, especially concerning school and health care, it is imperative to model this demand as a decision made by the parent or the caregiver. Thus, this study assumes that the parents derive utility from the child's health, and hence seeks the best care for the child during sickness using both market and non-market (behavioral) inputs through a utility maximizing process. This yields a demand for health function for the child, which is presented in the equation below for the purpose of estimation.

$$
\begin{aligned}
& \mathrm{H}=\beta Y+\pi S+\delta C+\varepsilon \\
& \text { Where: } \\
& \begin{aligned}
\mathrm{H} & =1: \text { Government facility } \\
& =2: \text { Private facility } \\
& =3: \text { Self-medication/Traditional }
\end{aligned}
\end{aligned}
$$

Where $Y$ represents child specific characteristics, such as gender and birth order, $\mathrm{S}$ represents socioeconomic factors of the mother/parents. These include wealth/income, education of the mother, health insurance status, marital status, and employment status. C represents environmental factors that affects health. These include residence (rural/urban), distance to nearest health facility, and transport to nearest health facility. $\beta, \pi$, and $\delta$ are vector of parameters associated with the explanatory variables. $H$ is the choice of facility for the treatment of childhood fever and $\varepsilon$ is the random disturbance term, which is assumed to be normally distributed.

The choice of treatment for fever is estimated using a multinomial response model (multinomial logistic/probit). The study seeks to model a mother's selection of a health care provider conditional on a child being sick with symptoms of fever. This is a discrete choice with more than two unordered outcomes. The multinomial response model follows a random utility framework. The assumption is that an individual chooses a given health care option only if the utility the individual derives from the chosen option is greater than the utility that can be derived from an alternative option. In this study, the multinomial probit model is used to avoid the assumption of the "independence of irrelevant alternatives (IIA)" inherent in the multinomial logit model. The IIA property in multinomial logit implies that the probability of choosing one health care option does not depend on the presence (or absence) of other options, which is not always true in the use of health care facilities. The choice of treatment from one facility mostly depends on the 
presence of an alternative and hence, using the multinomial logit model is likely to yield inconsistent and unreliable estimates.

\section{Presentation of Results}

The empirical analysis in this paper was done in two stages. The first is the univariate analysis using the Pearson's chi square test to test, whether there were significant differences between the treatment choices and the socioeconomic factors. The second was the multivariate analysis using the multinomial probit regression model to determine the factors that collectively determine the choice of treatment for childhood fevers among children-under age five in Ghana. The results are presented in Tables I and 2 respectively for the univariate and the multivariate analysis. It can be seen from Table I that, a majority of the people $(55.53 \%)$ rely on government health services, with $34.56 \%$ using private health care facilities for the treatment of childhood fever. Surprising, the practice of self-medication/ traditional health care is higher in the urban centres contrary to the believe that it is more prevalent in the rural centres. The use of traditional/selfmedication however falls with increasing education, but increases with the difficulty encountered in accessing formal health care as shown in the responses of those who reported difficulty in distance and transport to the nearest health care facility.

The results as presented in Table I of the univariate analysis indicates that there is a significant relationship between wealth, health insurance, residence (rural/urban), and access to health care (distance and transport to health facility) and the decision to seek appropriate care from any of the health facilities. . Majority of those within the richest health quintiles seek care from the government health facility. However, majority of those who fall within the richest quintile are shown to seek care from the private/mobile health facilities, with none of them seeking traditional care or self-medicating. Additionally, households with easy access to health care centres and those living within the urban communities are more likely to seek appropriate care from health facilities for the sick child. Moreover, households with health insurance are more likely to seek care for the sick child. 
Table I: Descriptive statistics with Pearson's chi square test

\begin{tabular}{|c|c|c|c|c|}
\hline $\begin{array}{l}\text { Explanatory Variables } \\
\text { Education }\end{array}$ & $\begin{array}{l}\text { Government hospital/ } \\
\text { Clinic/health centre }\end{array}$ & $\begin{array}{l}\text { Private/ } \\
\text { Mobile clinic }\end{array}$ & $\begin{array}{l}\text { Traditional/ } \\
\text { self-medication }\end{array}$ & $\begin{array}{l}\text { Pearson's } \\
\text { Chi square }\end{array}$ \\
\hline No education & 59.18 & 28.57 & 12.24 & $\operatorname{chi} 2(4)=6.26$ \\
\hline Primary & 48.6 & 40.19 & 11.21 & \\
\hline $\begin{array}{l}\text { Secondary/ Higher } \\
\text { Wealth Ouintile }\end{array}$ & 56.67 & 36.11 & 7.22 & \\
\hline Poorest & 58.72 & 20.18 & 21.1 & $\operatorname{chi} 2(8)=37.57^{*}$ \\
\hline Poorer & 56.12 & 36.73 & 7.14 & \\
\hline Middle & 53.01 & 34.94 & 12.05 & \\
\hline Richer & 58.43 & 38.2 & 3.37 & \\
\hline Richest & 47.27 & 52.73 & 0 & \\
\hline \multicolumn{5}{|l|}{ Health Insurance } \\
\hline Not insured & 69.65 & 25.87 & 4.48 & $\operatorname{chi} 2(2)=32.77^{*}$ \\
\hline Insured & 43.35 & 42.06 & 14.59 & \\
\hline \multicolumn{5}{|l|}{ Residence } \\
\hline Rural household & 49.45 & 46.7 & 3.85 & $\operatorname{chi} 2(2)=27.08 *$ \\
\hline Urban household & 59.92 & 25.79 & 14.29 & \\
\hline \multicolumn{5}{|l|}{ Employment status } \\
\hline Not working & 55.87 & 33.42 & 10.7 & $\operatorname{chi} 2(2)=3.39$ \\
\hline Working & 52.94 & 43.14 & 3.92 & \\
\hline \multicolumn{5}{|l|}{ Marital status } \\
\hline Not married & 56.35 & 33.86 & 9.79 & $\operatorname{chi} 2(2)=0.81$ \\
\hline Married & 50 & 39.29 & 10.71 & \\
\hline \multicolumn{5}{|l|}{ Distance } \\
\hline Not a problem & 51.32 & 40.4 & 8.28 & $\operatorname{chi} 2(2)=15.60 *$ \\
\hline Big problem & 65.15 & 21.21 & 13.64 & \\
\hline \multicolumn{5}{|l|}{ Transport } \\
\hline Not a problem & 50.82 & 39.67 & 9.51 & $\operatorname{chi} 2(2)=12.02 *$ \\
\hline Big problem & 66.67 & 22.48 & 10.85 & \\
\hline \multicolumn{5}{|l|}{ Gender of child } \\
\hline Male & 53.25 & 35.06 & 11.69 & $\operatorname{chi} 2(2)=2.08$ \\
\hline Female & 58.13 & 33.99 & 7.88 & \\
\hline Total (434) & 55.53 & 34.56 & 9.91 & \\
\hline
\end{tabular}

Degrees of freedom of chi square test in parenthesis

Table 2 further presents the results from the multivariate model where all the variables are combined to understand how they interplay in the decision to seek treatment for the sick child. The multinomial probit model is estimated using maximum likelihood technique. The multinomial model in this study considers three possible choices of treatment: Government health facility (health post, hospital or clinic), Private hospital/clinic or a mobile clinic, and Traditional medicine/ selfmedication. In this analysis, government facility is used as the reference point since all government health facilities accept health insurance. The categories in parenthesis in Table 2 are the reference categories, indicating the options for comparison of results. The variable marital status is coded into two sections; Married, and Not married (single, divorced, separated or widowed). The general idea behind this coding for marital status is trying to capture the effect staying with a partner currently may have on the decision to seek care for the child. 
African Population Studies Vol 28 no 2 Supplement July 2014

Table 2: Multinomial Probit regression (Reference: Government hospital/health Centre)

\begin{tabular}{|c|c|c|}
\hline VARIABLES & Private/ mobile clinic & $\overline{\text { Traditional/self-medication }}$ \\
\hline Wealth quintile & $\begin{array}{l}0.0914 \\
(0.0976)\end{array}$ & $\begin{array}{l}-0.307 * * \\
(0.137)\end{array}$ \\
\hline Age of mother & $\begin{array}{l}0.396 * \\
(0.221)\end{array}$ & $\begin{array}{c}\mathbf{0 . 8 7 2} * * * \\
(0.298)\end{array}$ \\
\hline Education of mother & $\begin{array}{l}-0.0924 \\
(0.132)\end{array}$ & $\begin{array}{l}0.0789 \\
(0.167)\end{array}$ \\
\hline Health Insurance (Reference: Not insured) & $\begin{array}{c}-0.981 * * * \\
(0.278)\end{array}$ & $\begin{array}{l}-0.206 \\
(0.473)\end{array}$ \\
\hline Gender of child (Reference: Male) & $\begin{array}{l}0.00294 \\
(0.187)\end{array}$ & $\begin{array}{l}-0.256 \\
(0.254)\end{array}$ \\
\hline Birth order of child & $\begin{array}{c}-0.165 * * * \\
(0.0609)\end{array}$ & $\begin{array}{c}-0.208 * * * \\
(0.0731)\end{array}$ \\
\hline Residence (Reference: rural) & $\begin{array}{l}-0.377 \\
(0.296)\end{array}$ & $\begin{array}{l}\mathbf{0 . 6 8 2 *} \\
(0.4 I I)\end{array}$ \\
\hline Rural with health insurance & $\begin{array}{l}-0.161 \\
(0.377)\end{array}$ & $\begin{array}{l}-1.217 * * \\
(0.583)\end{array}$ \\
\hline Employment (Reference: not working) & $\begin{array}{l}-0.0703 \\
(0.288)\end{array}$ & $\begin{array}{l}-0.823 * \\
(0.445)\end{array}$ \\
\hline Marital Status (Reference: Not Married) & $\begin{array}{l}-0.00572 \\
(0.270)\end{array}$ & $\begin{array}{l}-0.0684 \\
(0.378)\end{array}$ \\
\hline Distance to health Centre (big problem) & $\begin{array}{l}-0.411 \\
(0.280)\end{array}$ & $\begin{array}{l}0.222 \\
(0.399)\end{array}$ \\
\hline Transport to health Centre (big problem) & $\begin{array}{l}-0.275 \\
(0.275)\end{array}$ & $\begin{array}{l}-0.539 \\
(0.421)\end{array}$ \\
\hline Constant & $\begin{array}{l}-0.0270 \\
(0.601)\end{array}$ & $\begin{array}{c}-1.725 * * \\
(0.756)\end{array}$ \\
\hline $\begin{array}{l}\text { Number of observations }=434 \\
\text { Log likelihood }=-348.19608\end{array}$ & $\begin{array}{c}\text { Wald chi2(24) }= \\
\text { Prob }>\text { chi2 }=\end{array}$ & $\begin{array}{l}90.0 \\
0.0000\end{array}$ \\
\hline
\end{tabular}

The results from table two presents the coefficients from the multinomial probit analysis of the choice of treatment for the sick child. The results from the study indicate that wealth, age of the mother, health insurance status, birth order of the child, and residence are important predictors of the choice of treatment for childhood fevers in Ghana. The coefficient of wealth is positive and significant at the 5 percent level indicating that as wealth increases, mothers are less likely to seek for care from the traditional healers, or self-medication for the sick child, compared to seeking care from the government health facilities. Thus, mothers with higher wealth are more likely to take their sick child to the government health facility than to the traditional healer. The coefficient of wealth in the private/mobile clinics is positive but not significant. In addition, the age of the caretaker is positive for both private and traditional medicine in the study. Those with health insurance are also less likely to use the private facilities compared to the government facilities. This is not surprising as all government facilities accept health insurance, with just a select few private facilities that have been included in the scheme. Rural mothers have also been found to seek care from traditional healers, but this is different for the rural mothers with health insurance as the results is negative for such mothers indicating that they are more likely to seek care for the sick child from the government health facility compared to their counterparts who are not insured. Employed mothers are also less likely to seek traditional care for the sick child compared to their counterparts who are not working. Finally, birth order of the child is also negative for both private and traditional medicine.

\section{Discussion of results}

Wealth signifies economic power and ability to pay for health care for the sick child by the mother. The findings indicate that the household income/wealth is an important factor that influences the choice of facility for the treatment of childhood fever. Mothers tend to use the government health facilities with increasing wealth compared to self-medication or traditional health care than those in the poorest quintiles. The coefficient of wealth in the results for private is positive and negative for traditional/selfmedication. Thus, mothers who fall within the higher wealth quintiles are more likely to use government health facilities for the sick child. The 
coefficient on private health care is positive but not significant. Thus, the demand for care for the sick child is thus influenced by the wealth or income of the household within which the child is born and thus serves as an important predictor in the decision of the choice of health care facility for the child. This finding is in corroboration with earlier results that have also reported a positive association between the choice of facility for treatment and income/wealth by Filmer (2005), Arif (2007) and Novignon et al, 2010.

Furthermore, the results indicate that, mothers' in the rural areas are less likely to seek care for the sick child from a government health facility. This result might give two implications; either these mothers use the services rendered by the traditional healer because they cannot afford the charges of the government of private health care, or it might also be a signal of the unavailability of health care facilities in the communities. It is well known that, in Ghana as it is in other developing nations, one would have to travel over a distance to be able to access modern health care, especially for government health facility in the rural centers,. In addition, those with private health facilities that are close cannot also afford the services, hence, resort to the traditional healer who most of the time operates next door or is willing to offer services to the sick in the person's house. This is consistent with the findings of Kazembe et al, (2007) who reported that the treatment choices for fever are related to the place of residence in Malawi. The results however further indicate that rural residents with health insurance are less likely to use traditional medicine compared to the government health facilities. Thus, health insurance reduces the cost, at least direct cost, of assessing the government health facility compared to those who are not insured.

The results also indicate that the insured mother is more likely to seek for treatment for the sick child from a government facility than from the other sources, private or self-medication/traditional. This is significant at the one percent level in both results as presented in Table 2. Thus being insured increases the likelihood of seeking for appropriate care for the sick child from a government health facility. This is not surprising as mothers under the Ghana health insurance scheme have free access for the sick child under the age of 18 years. This therefore reduces at least the direct cost of treatment for the child and serves to encourage the mother to attend to the sick child, at least knowing that the direct cost is totally catered for or reduced.
Thus, whenever the child is sick, the insured mother can have free medical care for the child. Hence, it is not surprising that being insured influences the choice and the decision to seek care for the sick child. It can also be realized from the results that the rural mothers with health insurance are less likely to use traditional or self-medication for the sick child. This is very significant in the rural setting of the Ghanaian economy where most people in rural Ghana fall back on traditional or self-medication (often times asking friends and neighbors what type of medication will work for the sick child). Thus, providing people in rural Ghana with access to health insurance and of importance the availability of government health facility that offers and accepts the health insurance scheme will help improve the health of the rural poor in the nation.

Thus, as a policy measure, it is important to enhance the health insurance scheme in Ghana, and to encourage participation by all and sundry, especially in the rural areas to enroll and maintain their membership in the program to improve the health of children and people within the Ghanaian economy. This will probably help reduce the incidence of child mortality from preventable diseases and also the high rate of child morbidity in Ghana, and help Ghana achieve the MDG target of improving child health (to reduce child mortality by 75 percent by 2015). This finding is consistent with earlier results from the study by Novignon et al, (2010) who also reported a positive association between health insurance and the use of public health facilities for the treatment of childhood fever in rural Ghana.

The results further indicate that the probability of seeking for care is highly related to the birth order of the child. Interestingly, parents are more likely to seek for care from a government facility for higher births, thus, more likely to seek for care from a government facility as the number of children increases. This presents an interesting situation, but the probably reason may be that with increased number of children, it becomes easier to get someone to take care of the remaining kids when the mother has taken the sick child to the hospital due to the work schedule of these mothers, mostly working in the informal sector. In addition, it might also be an indication of building trust in the formal health sector with an increasing number of children, thus necessitating the use of the formal system for later births. This is in contrasts to what is mostly observed where mothers administer drugs of the older ones to the younger ones upon seeing similar 
symptoms of the previous child with the assumption of the same type of sickness repeating itself.

Finally, the age of the mother shows that the older mothers are more likely to use the traditional healers, or self-medication for the sick child compared to using the government health facility. This result is not very surprising in the context of a developing country like Ghana where some of the older people still believe in the use of traditional medicine compared to orthodox medicine for the treatment of diseases. This concurs with the findings of Kazembe et al, (2007) reporting that the treatment options are related with the age of the mother/care-giver.

Working mothers are more likely to use the government health facilities for the sick child as indicated in the results. This may be because those in the formal sector are either insured under the national health insurance, or have been insured under a private arrangement by the employer thus, reducing the cost of care, and also are able to seek for permission to attend to the sick child. Thus, the social environment of the mother/caregiver is important in the event of seeking care for the sick child and hence, need to be considered in any policy that intends to improve the lot of children in the Ghanaian community and probably in other developing nations like Ghana.

\section{Conclusion}

The study set out to investigate the socioeconomic factors that influence the decision to seek care for the sick child in Ghana. In doing so, the Grossman health care model was utilized by maximizing the utility of the mother/caretaker with the health of the child as an argument in the utility function. The multinomial probit model was employed, by identifying important factor that have been used in the literature and in theory that are known to influence such choices. The results indicate that the decision to seek care and the choice of treatment for the sick child is influenced by wealth, birth order of the child, age of the mother, health insurance status of the mother, residence, and the employment status of the mother. Thus, policy should be able to address such factors that also affect the decision to seek care for the sick child, especially with the aspect of health insurance for those in the rural centers, in the quest to improve health and to achieve the targets set in the MDGs for Ghana.

In general, wealthier mothers have been found to utilize government health care services for the sick child. This is probably due to the cost associated with obtaining care for the sick child. Even though wealth/incomes may not be easily influenced in the short term by policy, it might be necessary to put in place long-term policies that would improve the incomes and wealth of households, and make effort to reduce the cost of health care for children, especially from the deprived homes. One of such that needs to be strengthened is the health insurance scheme in Ghana, which should be well managed to achieve the set target for the scheme in term of coverage and efficiency. This is based on the significance of the health insurance scheme in influencing the decision to seek care, especially for those in rural Ghana. However, this should be accompanied by the establishment of government health centers and health posts in the rural communities to make it accessible for the people within such communities.

\section{References}

Arif, G. M. (2004). Child health and poverty in Pakistan. The Pakistan Development Review, 2II238.

Chibwana, A. I., Mathanga, D. P., Chinkhumba, J., \& Campbell, C. H. (2009). Socio-cultural predictors of health-seeking behaviour for febrile under-five children in Mwanza-Neno district, Malawi. Malaria journal, 8(I), 219.

Elo, I. T. (1992).Utilization of maternal health-care services in Peru: the role of women's education. Health Transition Review, 49-69.

Filmer, D. (2005). Fever and its treatment among the more and less poor in sub-Saharan Africa. Health policy and planning, 20(6), 337-346.

Ghana Statistical Service (GSS): Noguchi Memorial Institute for Medical Research(NMIMR), and ORC Macro: Ghana Demographic and Health Survey 2008.

Calverton, Maryland: GSS, NMIMR, and MI; 2009.

Goldman, N., Pebley, A. R., \&Gragnolati, M. (2002).Choices about treatment for ARI and diarrhea in rural Guatemala. Social Science \& Medicine, 55(10), 1693-17I2.

Grossman, M. (1972).On the concept of health capital and the demand for health. The Journal of Political Economy, 223-255.

Kazembe, L. N., Appleton, C. C., \&Kleinschmidt, I. (2007).Choice of treatment for fever at household level in Malawi: examining spatial patterns. Malaria Journal, 6(I), 40.

Malik, E. M., Hanafi, K., Ali, S. H., Ahmed, E. S., \& Mohamed, K. A. (2006). Treatment-seeking 
behaviour for malaria in children under five years of age: implication for home management in rural areas with high seasonal transmission in Sudan. Malaria journal, 5(I), 60.

Nonvignon, J., Aikins, M. K., Chinbuah, M. A., Abbey, M., Gyapong, M., Garshong, B. N., ...\&Gyapong, J. O. (20I0). Research Treatment choices for fevers in children under-five years in a rural Ghanaian district. Malaria Journal

Rutebemberwa, E., Pariyo, G., Peterson, S., Tomson, G., \&Kallander, K. (2009).Utilization of public or private health care providers by febrile children after user fee removal in Uganda. Malaria journal, 8(I), 45.
UNICEF, and WHO (2004). Low Birth Weight: Country, Regional and Global Estimates. New York

World Health Organization (2006) Multicenter Growth Reference Study Group (MGRS)

WHO Child growth standards: Length/height-forage, weight-for-age, weight-forlength, weightfor-height and body mass index-for-age: Methods and development.

Geneva: World Health Organization.

World Health Organization: World Malaria Report 2008. Geneva: World Health

Organization; 2008. World Health Organisation (WHO), 20II. "Investing in healthfor Africa: The case for strengthening systems for better health outcomes".

Harmonisation for health in Africa. 